DOI: $10.36910 / 6775-2524-0560-2019-36-13$

УДК 004.415.3

Пех П.А., Гайдучик С.I, Чимрук Н.О.

Луцький національний технічний університет

\title{
ДОСЛІДЖЕННЯ ПРОЦЕСУ ФУНКЦІОНУВАННЯ АВТОМАТИЗОВАНИХ ЛІНІЙ МЕТОДОМ ІМІТАЦЙНОГО МОДЕЛЮВАННЯ
}

Пех П. А., Гайдучик С. І., Чимрук Н. О. Дослідження процесу функціонування автоматизованих ліній методом імітаційного моделювання. В статті наведені результати дослідження процесу функціонування автоматизованої лінії зі стохастичним характером роботи методом імітаційного моделювання. експеримент

Ключові слова: C++Builder проект, автоматизована лінія, розподіл Ерланга, імітаційна модель, кібертнетичний

Пех П. А., Гайдучик С. И., Чимрук Н. О. Исследование процесса функционирования автоматизированных линий методом имитационного моделирования. В статье приведены результаты исследования процесса функционирования автоматизированной линии со стохастическим характером работ методом имитационного моделирования.

Ключевые слова: C++Builder проект, входящий поток, распределение Эрланга, имитационная модель, кибернетический эксперимент

Pekh Petro, Gaiduchyk Sergij, Chymruk Nazar. Investigation of the process of automated lines functioning by the simulation method. The article presents the results of the investigation of the functioning process of automated line with stochastic work nature by the simulation modeling method.

Keywords: C++Builder project, automated line, Erlang distribution, simulation model, cybernetic experiment.

Постановка задачі. Розглянемо процес функціонування автоматизованої лінії зі стохастичним характером функціонування, яка складається із s послідовно 3'єднаних верстатів, між якими встановлені буферні пристрої певної місткості (рис. 1), для якої нами розроблено імітаційний програмний комплекс [1]. Процеси надходження предметів праці (заготовок) та їх оброблення на верстатах автоматизованої лінії вважаються випадковими - а саме такими, що описуються розподілом Ерланга. Вважаються відомими (заданими) наступні параметри досліджуваної лінії:

кількість s верстатів, що входять до складу лінії;

номінальні продуктивності кожного верстату;

параметри стабільності робочих циклів (параметри Ерланга) кожного верстату;

місткості буферних пристроїв між верстатами.

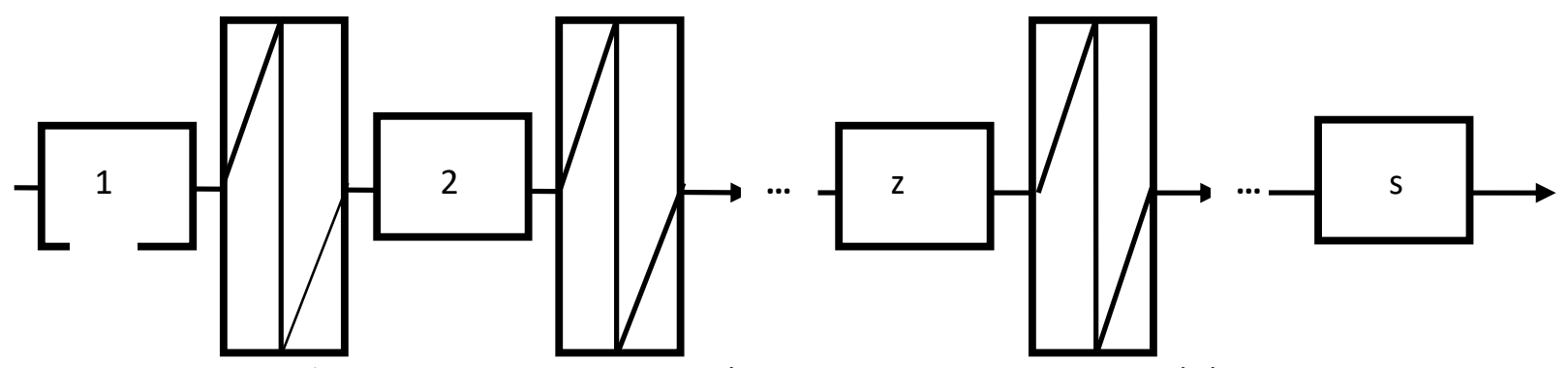

Рис.1 - Структурна схема досліджуваної автоматизованої лінії

Метою даного дослідження $є$ отримання залежностей значення коефіцієнта використання робочого часу $\rho$ автоматизованої лінії від кількості s верстатів, параметра стабільності робочих циклів верстатів $\mathrm{k}$ та місткості буферних пристроїв М за допомогою розробленої нами імітаційної моделі.

Основна частина. Планом передбачалося проведення комплексу досліджень роботи автоматизованих ліній на створеній нами імітаційній моделі. У даній статті викладені результати цих досліджень та їх аналіз.

Дослідження залежності коефіціснта використання робочого часу $\rho$ автоматизованої лінії від параметра стабільності робочих циклів верстатів $\mathrm{k}$ за фіксованих значеннях s та М.

У таблиці 1 наведено значення коефіцієнта використання робочого часу $\rho$ автоматизованої лінії, що складається з s верстатів, від параметра стабільності робочих циклів верстатів $\mathrm{k}(\mathrm{k}=1 . .20)$ за різних значень місткості буферних пристроїв $\mathrm{M}(\mathrm{M}=0 ; \mathrm{M}=5 ; \mathrm{M}=10)$. За результатами імітаційного моделювання побудовані графіки залежностей коефіцієнта використання робочого часу лінії (рис. 3.1 
- 3.3) від параметра стабільності робочих циклів верстатів $\mathrm{k}$ за різних значень місткості буферних пристроїв М та кількості верстатів s.

Таблиця 1 - Залежність коефіцієнта використання робочого часу $\rho$ автоматизованої лінії від параметра k та фіксованих значеннях s та M

\begin{tabular}{|c|c|c|c|c|c|c|c|c|c|}
\hline \multirow{3}{*}{$\begin{array}{l}\text { Пара- } \\
\text { метр k }\end{array}$} & \multicolumn{9}{|c|}{ Коефіцієнт використання робочого часу лінії $\rho$} \\
\hline & \multicolumn{3}{|c|}{ Лінія з s=2 верстатів } & \multicolumn{3}{|c|}{ Лінія з s=6 верстатів } & \multicolumn{3}{|c|}{ Лінія з $\mathrm{s}=10$ верстатів } \\
\hline & $\mathrm{M}=0$ & $\mathrm{M}=5$ & $\mathrm{M}=10$ & $\mathrm{M}=0$ & $\mathrm{M}=5$ & $\mathrm{M}=10$ & $\mathrm{M}=0$ & $\mathrm{M}=5$ & $\mathrm{M}=10$ \\
\hline 1 & 0,666 & 0,782 & 0,869 & 0,512 & 0,634 & 0,728 & 0,363 & 0,491 & 0,591 \\
\hline 2 & 0,687 & 0,800 & 0,885 & 0,537 & 0,656 & 0,746 & 0,390 & 0,515 & 0,612 \\
\hline 3 & 0,707 & 0,817 & 0,899 & 0,560 & 0,676 & 0,764 & 0,416 & 0,539 & 0,633 \\
\hline 4 & 0,727 & 0,834 & 0,912 & 0,582 & 0,695 & 0,780 & 0,442 & 0,561 & 0,652 \\
\hline 5 & 0,745 & 0,849 & 0,924 & 0,603 & 0,713 & 0,795 & 0,466 & 0,582 & 0,670 \\
\hline 6 & 0,762 & 0,863 & 0,935 & 0,623 & 0,731 & 0,809 & 0,489 & 0,603 & 0,688 \\
\hline 7 & 0,778 & 0,876 & 0,945 & 0,642 & 0,747 & 0,823 & 0,511 & 0,622 & 0,704 \\
\hline 8 & 0,793 & 0,888 & 0,955 & 0,660 & 0,762 & 0,835 & 0,532 & 0,640 & 0,719 \\
\hline 9 & 0,806 & 0,899 & 0,963 & 0,677 & 0,776 & 0,846 & 0,552 & 0,657 & 0,733 \\
\hline 10 & 0,819 & 0,909 & 0,969 & 0,693 & 0,789 & 0,856 & 0,571 & 0,673 & 0,746 \\
\hline 11 & 0,831 & 0,917 & 0,975 & 0,708 & 0,801 & 0,865 & 0,589 & 0,688 & 0,758 \\
\hline 12 & 0,842 & 0,925 & 0,980 & 0,722 & 0,812 & 0,873 & 0,606 & 0,702 & 0,769 \\
\hline 13 & 0,852 & 0,932 & 0,984 & 0,735 & 0,822 & 0,880 & 0,622 & 0,715 & 0,779 \\
\hline 14 & 0,860 & 0,938 & 0,987 & 0,747 & 0,830 & 0,886 & 0,637 & 0,727 & 0,788 \\
\hline 15 & 0,868 & 0,943 & 0,989 & 0,757 & 0,838 & 0,890 & 0,651 & 0,738 & 0,796 \\
\hline 16 & 0,875 & 0,946 & 0,989 & 0,767 & 0,845 & 0,894 & 0,664 & 0,748 & 0,803 \\
\hline 17 & 0,880 & 0,949 & 0,989 & 0,776 & 0,851 & 0,897 & 0,675 & 0,756 & 0,809 \\
\hline 18 & 0,885 & 0,950 & 0,989 & 0,783 & 0,855 & 0,899 & 0,686 & 0,764 & 0,814 \\
\hline 19 & 0,888 & 0,951 & 0,990 & 0,790 & 0,859 & 0,899 & 0,696 & 0,771 & 0,818 \\
\hline 20 & 0,891 & 0,951 & 0,990 & 0,795 & 0,862 & 0,899 & 0,704 & 0,777 & 0,820 \\
\hline
\end{tabular}

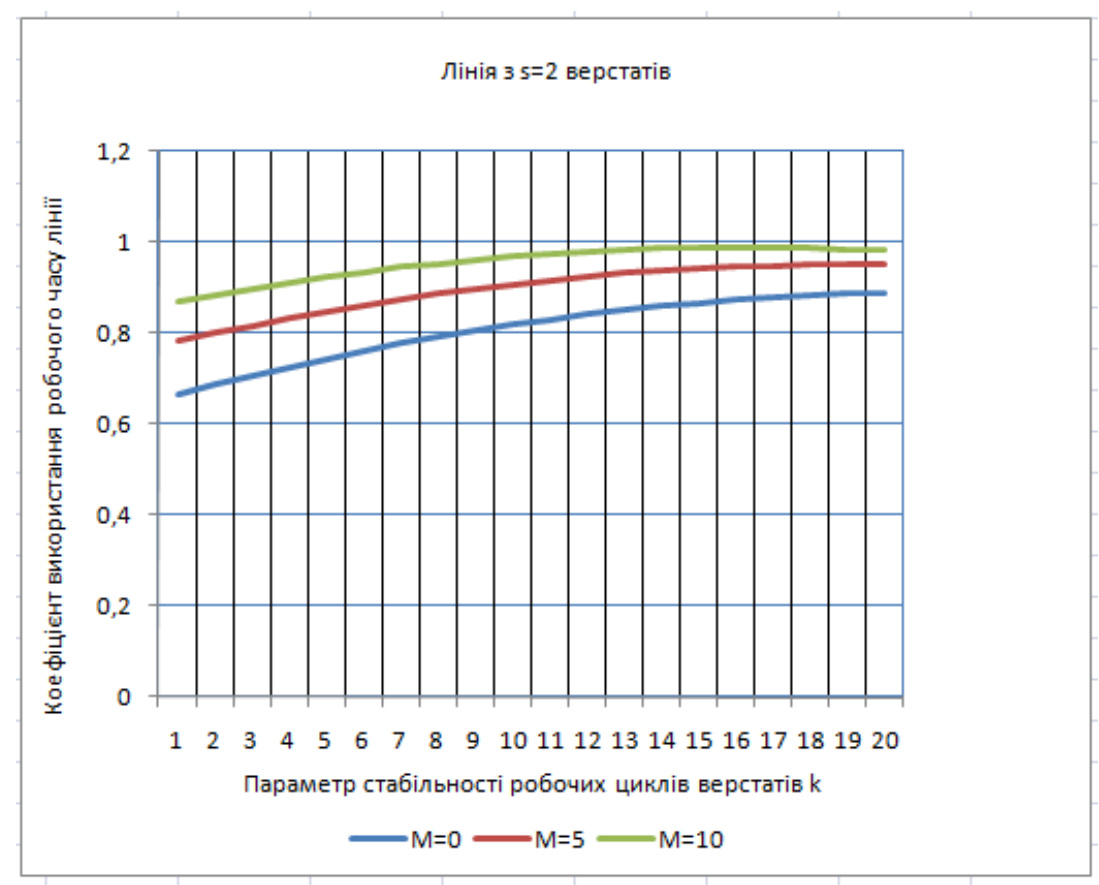

Рис. 2 - Залежність коефіцієнта використання робочого часу автоматизованої лінії з двох верстатів від параметра стабільності робочого часу верстатів для трьох випадків місткості буферних пристроїв 


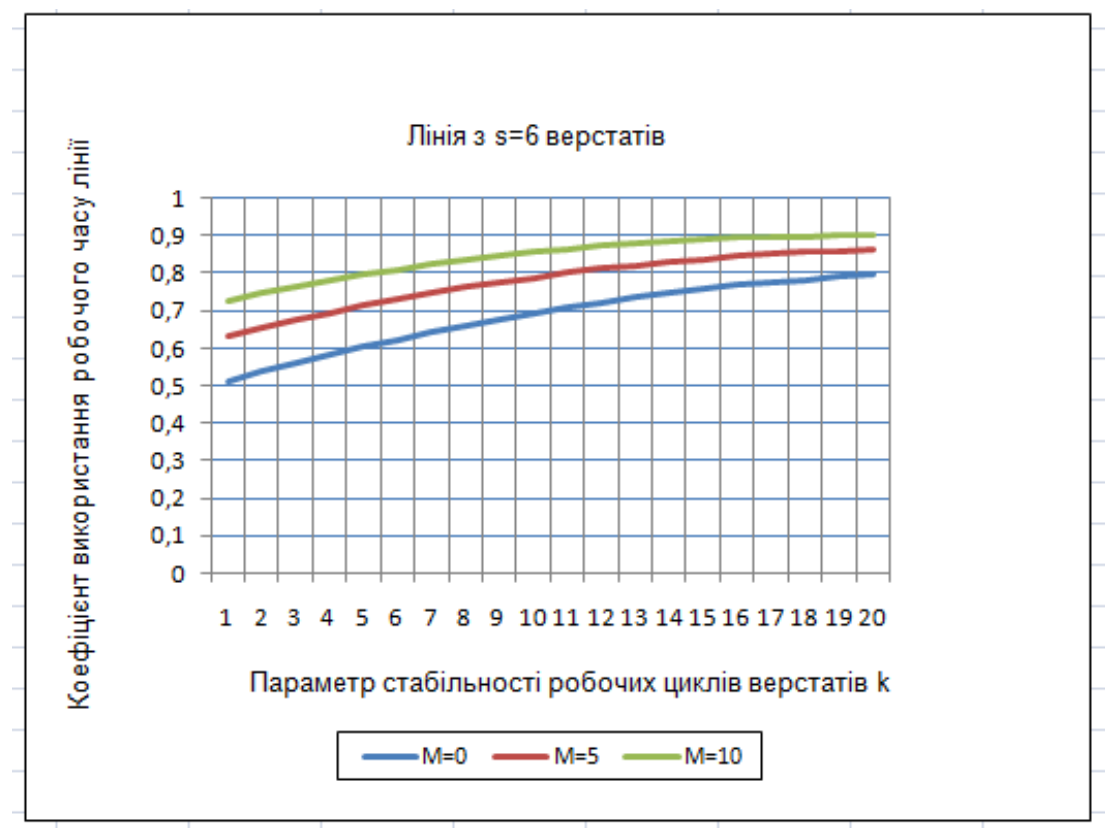

Рис. 3 - Залежність коефіцієнта використання робочого часу автоматизованої лінії з шести верстатів від параметра стабільності робочого часу верстатів для трьох випадків місткості буферних пристроїв

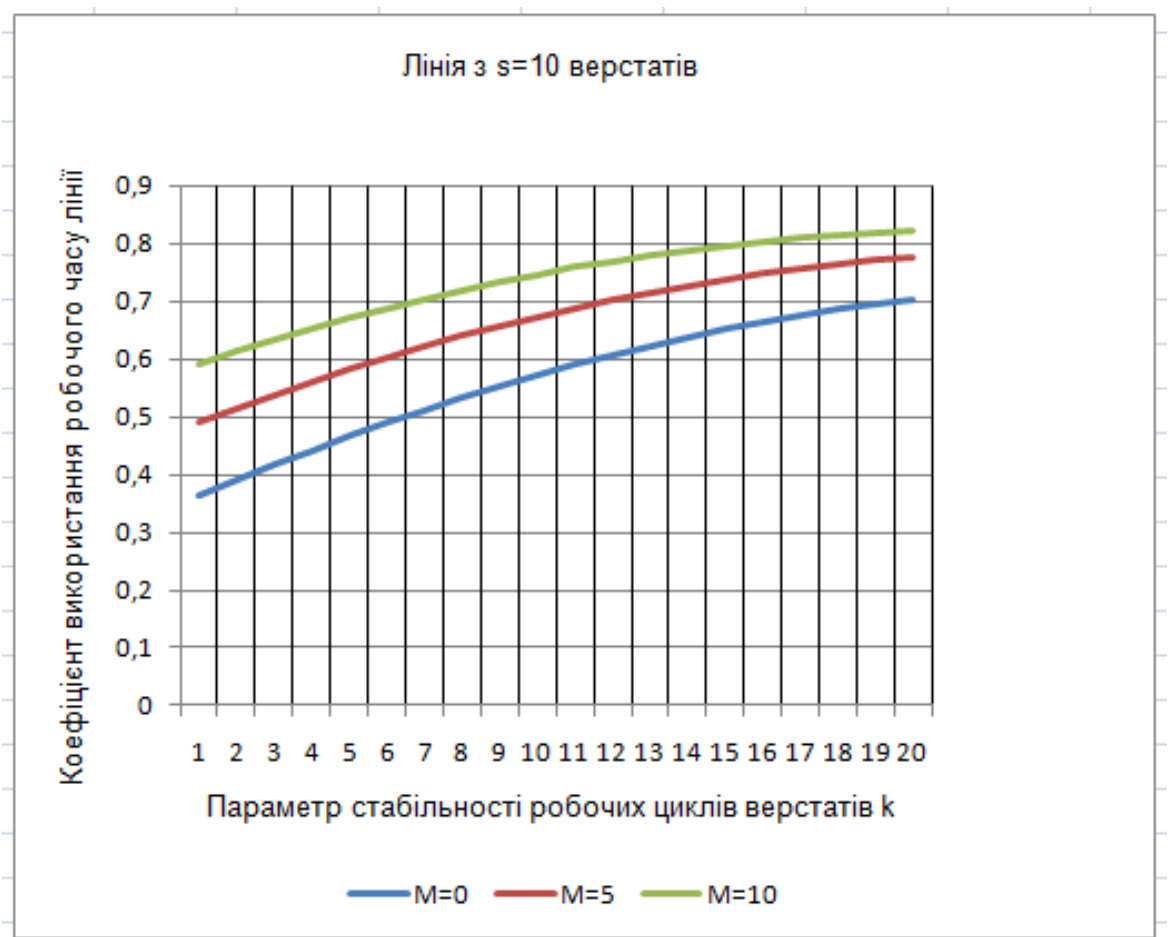

Рис. 4 - Залежність коефіцієнта використання робочого часу автоматизованої лінії з шести верстатів від параметра стабільності робочого часу верстатів для трьох випадків місткості буферних пристроїв

Аналіз даних таблиці 1 та графічних залежностей , навежених на рис. 2 - 4, дає змогу зробити наступні висновки.

Величина коефіцієнта використання робочого часу $\rho$ автоматизованої лінії, що складається 3 двох верстатів, зростає:

у випадку жорсткого з'єднання верстатів $(\mathrm{M}=0)$ від $\rho=0,666$ при $\mathrm{k}=1$ до $\rho=0,891$ при $\mathrm{k}=20$;

у випадку гнучкого з'єднання верстатів $(\mathrm{M}=5)$ від $\rho=0,782$ при $\mathrm{k}=1$ до $\rho=0,951$ при $\mathrm{k}=20$;

у випадку збільшення місткості буферних пристроїв $(\mathrm{M}=10)$ від $\rho=0,869$ при $\mathrm{k}=1$ до $\rho=0,990$ при $\mathrm{k}=20$.

Величина коефіцієнта використання робочого часу $\rho$ автоматизованої лінії, що складається 3 шести верстатів, зростає: 
у випадку жорсткого з'єднання верстатів ( $\mathrm{M=0}$ ) від $\rho=0,512$ при $\mathrm{k}=1$ до $\rho=0,795$ при $\mathrm{k}=20$;

у випадку гнучкого з'єднання верстатів $(\mathrm{M}=5)$ від $\rho=0,634$ при $\mathrm{k}=1$ до $\rho=0,862$ при $\mathrm{k}=20$; при $\mathrm{k}=20$.

у випадку збільшення місткості буферних пристроїв $(\mathrm{M}=10)$ від $\rho=0,728$ при $\mathrm{k}=1$ до $\rho=0,899$

Величина коефіцієнта використання робочого часу $\rho$ автоматизованої лінії, що складається 3 десяти верстатів, зростає:

у випадку жорсткого з'єднання верстатів $(\mathrm{M}=0)$ від $\rho=0,363$ при $\mathrm{k}=1$ до $\rho=0,704$ при $\mathrm{k}=20$;

у випадку гнучкого з'єднання верстатів $(\mathrm{M}=5)$ від $\rho=0,491$ при $\mathrm{k}=1$ до $\rho=0,777$ при $\mathrm{k}=20$; при $\mathrm{k}=20$.

у випадку збільшення місткості буферних пристроїв $(\mathrm{M}=10)$ від $\rho=0,591$ при $\mathrm{k}=1$ до $\rho=0,820$

Таким чином, параметр стабільності робочого циклу істотно впливає на значення коефіцієнта використання робочого часу автоматизованої лінії. Найбільше цей вплив помітний у випадку жорсткого з'єднання верстатів. Як ми вже зазначали, у випадку жорсткого з'єднання двох верстатів коефіцієнт використання робочого часу може бути збільщений на $22.5 \%$. Це означає, що на таку величину збільшиться випуск продукції лише за рахунок мір, які забезпечують зростання параметра стабільності робочого циклу. Наприклад, за рахунок більш ретельного сортування сировини, більш якісної підготовки інструменту та інших міроприємств, що впливають на стабільність роботи лінії.

Дослідження залежності коефіціснта використання робочого часу $\rho$ автоматизованої лінії, що складається $3 \mathrm{~s}$ верстатів, від місткості буферних пристроїв М за різних значень параметра стабільності робочих циклів верстатів $\mathrm{k}$.

У таблиці 2 наведено значення коефіцієнта використання робочого часу $\rho$ автоматизованої лінії, що складається $3 \mathrm{~s}(\mathrm{~s}=2 ; \mathrm{s}=6 ; \mathrm{s}=10)$ верстатів, від місткості буферних пристроїв $\mathrm{M}(\mathrm{M}=0 . .20)$ за різних значень параметра стабільності робочих циклів верстатів $\mathrm{k}(\mathrm{k}=1 ; \mathrm{k}=5 ; \mathrm{k}=10)$. За результатами імітаційного моделювання побудовані графіки залежностей коефіцієнта використання робочого часу лінії (рис. 3.4 - 3.6) від параметра М при фіксованих значеннях параметра стабільності робочих циклів верстатів k та кількості верстатів $\mathrm{s}$.

Таблиця 2 - Залежність коефіцієнта використання робочого часу $\rho$ автоматизованої лінії, що складається з s верстатів, від місткості буферних пристроїв М за різних значень стабільності робочих циклів верстатів $\mathrm{k}$

\begin{tabular}{|l|l|l|l|l|l|l|l|l|l|}
\hline \multirow{2}{*}{$\begin{array}{l}\text { Пара- } \\
\text { метр М }\end{array}$} & \multicolumn{9}{|c|}{ Коефіціснт використання робочого часу лінї $\rho$} \\
\cline { 2 - 10 } & \multicolumn{2}{|c|}{ Лінія з s=2 верстатів } & \multicolumn{3}{c|}{ Лінія 3 $=6$ верстатів } & \multicolumn{3}{c|}{ Лінія з s=10 верстатів } \\
\cline { 2 - 10 } & $\mathrm{k}=1$ & $\mathrm{k}=5$ & $\mathrm{k}=10$ & $\mathrm{k}=1$ & $\mathrm{k}=5$ & $\mathrm{k}=10$ & $\mathrm{k}=1$ & $\mathrm{k}=5$ & $\mathrm{k}=10$ \\
\hline 0 & 0,666 & 0,745 & 0,799 & 0,512 & 0,593 & 0,647 & 0,363 & 0,426 & 0,470 \\
\hline 1 & 0,691 & 0,763 & 0,814 & 0,536 & 0,614 & 0,665 & 0,386 & 0,468 & 0,507 \\
\hline 2 & 0,715 & 0,787 & 0,835 & 0,563 & 0,643 & 0,691 & 0,415 & 0,488 & 0,536 \\
\hline 3 & 0,739 & 0,808 & 0,854 & 0,588 & 0,660 & 0,707 & 0,441 & 0,509 & 0,554 \\
\hline 4 & 0,760 & 0,824 & 0,866 & 0,608 & 0,674 & 0,717 & 0,461 & 0,529 & 0,571 \\
\hline 5 & 0,780 & 0,841 & 0,880 & 0,630 & 0,690 & 0,730 & 0,483 & 0,544 & 0,583 \\
\hline 6 & 0,800 & 0,858 & 0,895 & 0,651 & 0,709 & 0,745 & 0,506 & 0,564 & 0,600 \\
\hline 7 & 0,819 & 0,875 & 0,908 & 0,671 & 0,726 & 0,760 & 0,527 & 0,582 & 0,616 \\
\hline 8 & 0,836 & 0,890 & 0,920 & 0,689 & 0,743 & 0,773 & 0,547 & 0,600 & 0,630 \\
\hline 9 & 0,853 & 0,904 & 0,931 & 0,707 & 0,758 & 0,786 & 0,565 & 0,616 & 0,644 \\
\hline 10 & 0,868 & 0,917 & 0,941 & 0,723 & 0,772 & 0,797 & 0,583 & 0,632 & 0,656 \\
\hline 11 & 0,882 & 0,928 & 0,950 & 0,739 & 0,785 & 0,807 & 0,600 & 0,646 & 0,668 \\
\hline 12 & 0,895 & 0,939 & 0,957 & 0,753 & 0,797 & 0,815 & 0,615 & 0,659 & 0,678 \\
\hline 13 & 0,907 & 0,948 & 0,964 & 0,766 & 0,808 & 0,823 & 0,629 & 0,671 & 0,687 \\
\hline 14 & 0,917 & 0,957 & 0,969 & 0,778 & 0,817 & 0,830 & 0,642 & 0,682 & 0,694 \\
\hline 15 & 0,927 & 0,964 & 0,973 & 0,789 & 0,825 & 0,835 & 0,654 & 0,691 & 0,701 \\
\hline 16 & 0,935 & 0,970 & 0,976 & 0,798 & 0,833 & 0,839 & 0,665 & 0,700 & 0,707 \\
\hline 17 & 0,942 & 0,975 & 0,978 & 0,807 & 0,839 & 0,843 & 0,675 & 0,707 & 0,711 \\
\hline 18 & 0,948 & 0,978 & 0,979 & 0,814 & 0,844 & 0,845 & 0,683 & 0,713 & 0,714 \\
\hline 19 & 0,953 & 0,981 & 0,979 & 0,820 & 0,848 & 0,846 & 0,691 & 0,718 & 0,716 \\
\hline 20 & 0,957 & 0,982 & 0,977 & 0,825 & 0,850 & 0,845 & 0,697 & 0,722 & 0,717 \\
\hline
\end{tabular}


Аналіз даних таблиці 2, дає змогу зробити наступні висновки.

Величина коефіцієнта використання робочого часу $\rho$ автоматизованої лінії, що складається 3 двох верстатів, зростає: $M=20$;

у випадку параметра стабільності роботи верстатів $\mathrm{k}=1$ від $\rho=0,666$ при $\mathrm{M}=0$ до $\rho=0,982$ при

у випадку параметра стабільності роботи верстатів $\mathrm{k}=5$ від $\rho=0,745$ при $\mathrm{M}=0$ до $\rho=0,891$ при $M=20$;

у випадку параметра стабільності роботи верстатів $\mathrm{k}=10$ від $\rho=0,799$ при $\mathrm{M}=0$ до $\rho=0,977$ при $\mathrm{M}=20$.

Величина коефіцієнта використання робочого часу $\rho$ автоматизованої лінії, що складається 3 шести верстатів, зростає:

у випадку параметра стабільності роботи верстатів $\mathrm{k}=1$ від $\rho=0,562$ при $\mathrm{M}=0$ до $\rho=0,825$ при $\mathrm{M}=20$;

у випадку параметра стабільності роботи верстатів $\mathrm{k}=5$ від $\rho=0,593$ при $\mathrm{M}=0$ до $\rho=0,850$ при $\mathrm{M}=20$; $\mathrm{M}=20$.

у випадку параметра стабільності роботи верстатів $\mathrm{k}=10$ від $\rho=0,647$ при $\mathrm{M}=0$ до $\rho=0,845$ при

Величина коефіцієнта використання робочого часу $\rho$ автоматизованої лінії, що складається 3 десяти верстатів, зростає:

$M=20$;

у випадку параметра стабільності роботи верстатів $\mathrm{k}=1$ від $\rho=0,363$ при $\mathrm{M}=0$ до $\rho=0,697$ при $M=20$;

у випадку параметра стабільності роботи верстатів $\mathrm{k}=5$ від $\rho=0,426$ при $\mathrm{M}=0$ до $\rho=0,722$ при

у випадку параметра стабільності роботи верстатів $\mathrm{k}=10$ від $\rho=0,470$ при $\mathrm{M}=0$ до $\rho=0,717$ при $\mathrm{M}=20$.

Таким чином, місткість буферних пристроїв істотно впливає на значення коефіцієнта використання робочого часу автоматизованої лінії. Найбільше цей вплив помітний у випадку низької стабільності роботи верстатів $(\mathrm{k}=1)$. Як ми вже зазначали, у випадку параметра стабільності роботи верстатів $(\mathrm{k}=1)$ коефіцієнт використання робочого часу може бути збільщений на $31.6 \%$. Це означає, що на таку величину збільшиться випуск продукції лише за рахунок встановлення між верстатами буферного пристрою місткістю 20 заготовок.

Зазначимо, що результати досліджень автоматизованих ліній, що наведені в даній статті, добре узгоджуються з отриманими іншими дослідниками за допомогою інших моделей $[2,3]$.

\section{Висновки}

В роботі наведені результати дослідження процесу функціонування автоматизованої лінії зі стохастичним характером роботи. Зокрема, отримані:

залежності коефіцієнта використання робочого часу $\rho$ автоматизованої лінії від параметра $\mathrm{k}$ та фіксованих значеннях s та M

залежності коефіцієнта використання робочого часу $\rho$ автоматизованої лінії, що складається з $\mathrm{s}$ верстатів, від місткості буферних пристроїв М за різних значень стабільності робочих циклів верстатів $\mathrm{k}$

1. Пех П.А., Войтович А.О. Програмний С++комплекс для дослідження процесу функціонування автоматизованих ліній та його верифікація. Науковий журнал Комп'ютерно-інтегровані технології: освіта, науука, виробництво . Луцьк, РВВ Луцького НТУ,2017. №27. Стор.60 - 67.

2. Д.Л. Дудюк та інші. Моделювання та оптимізація об’єктів і систем керування: Навчальний посібник для студентів вищих навчальних закладів. -К.:IЗМН, 1998.-248 с.

3. Дудюк Дмитро та інші. Елементи теорії автоматичних ліній Навчальний посібник для студентів вищих навчальних закладів. -Київ-Львів:ІЗМН, 1998.-192 с.

1. Pech PA, Voitovich AA Software $\mathrm{C}++$ complex for investigation of the process of functioning of automated lines and its verification. Scientific journal Computer-Integrated Technologies: Education, Science, Production. -Lutsk, RVV of Lutsk NTU, 2017. №27. Pages 60 - 67.

2. D.L. Dudyuk and others. Simulation and optimization of objects and control systems: A tutorial for university students. $-\mathrm{K}$.: MOD, 1998. - 248 p.

3. Dudyuk Dmitry and others. Elements of the theory of automatic lines A textbook for students of higher educational establishments. -Kyiv-Lviv: ISMN, 1998.-192 p. 